\title{
12p12.1 microdeletion syndrome
}

INSERM

\section{Source}

INSERM. (1999). Orphanet: an online rare disease and orphan drug data base. 12p12.1 microdeletion syndrome. ORPHA:313884

12 p12.1 microdeletion syndrome is a rare chromosomal anomaly syndrome, resulting from the partial deletion of the short arm of chromosome 12, characterized by intellectual disability, global developmental delay with prominent language impairment, behavioral abnormalities and mild facial dysmorphism (incl. frontal bossing, downslanting palpebral fissures, epicanthal folds, broad, depressed nasal bridge with bulbous nasal tip, low-set ears with underdeveloped helices). Other associated features may include skeletal abnormalities (butterfly vertebrae, scoliosis), strabismus, optic nerve hypoplasia, and brain malformations. 